\title{
Nitric oxide-induced headache may arise from extracerebral arteries as judged from tolerance to isosorbide-5-mononitrate
}

\author{
Ingelise Christiansen · Helle K. Iversen • \\ Jes Olesen · Peer Tfelt-Hansen
}

Received: 4 April 2008/Accepted: 5 May 2008/Published online: 3 June 2008

(C) Springer-Verlag 2008

\begin{abstract}
Long-term exposure to organic nitrates influences different sections of the vascular bed heterogeneously. Continuous dosage of nitrates leads to the development of tolerance both to the vascular effects and to the unwanted adverse effect, headache. Human data on the development of tolerance in different cranial arteries over more than $24 \mathrm{~h}$ are lacking. We compared the vascular changes of the middle cerebral, superficial temporal and radial arteries during oral administration of isosorbide-5-mononitrate (5-ISMN) $30 \mathrm{mg}$ three times daily for 7 days in 11 healthy subjects in a double-blind, randomised, placebo controlled cross-over design. Blood velocity in the middle cerebral artery was measured with transcranial Doppler and the diameters of the temporal and radial arteries were measured with high frequency ultrasound. Headache recordings were compared to the observed vascular changes over time. Tolerance was complete within $24 \mathrm{~h}$ in the middle cerebral artery whilst in the superficial temporal and the radial arteries, tolerance was only partial and developed much more slowly, i.e. after 7 days correlating with the disappearance of NOinduced headache. The present study thus demonstrated the important differences in the time profiles of appearance of nitrate tolerance in arteries of different vascular beds in man. If vasodilatation is the cause of NO-induced headache the results point to extracerebral arteries as the locus of nociception. Due to a variety of other possible
\end{abstract}

I. Christiansen · H. K. Iversen · J. Olesen · P. Tfelt-Hansen ( $\square)$ Department of Neurology, Glostrup Hospital, University of Copenhagen, 2600 Glostrup, Denmark e-mail: tfelt@inet.uni2.dk pain-inducing effects of nitric oxide our results do not exclude cerebral arteries.

Keywords Nitrate tolerance $\cdot$ Nitric oxide $\cdot$ Arteries . Headache · Isosorbide-5-mononitrate

\section{Introduction}

Glyceryl trinitrate (GTN) (nitroglycerin) and isosorbide5-mononitrate (5-ISMN) have similar mechanisms of actions and exert their effects through their active metabolite nitric oxide (NO) [1] which is a potent regulator of vascular tone [2]. Both drugs possess a wellknown ability to provoke a vascular type headache in healthy subjects $[3,4]$. In sufferers of migraine GTN induces migraine attacks which are clinically identical to spontaneous attacks, indicating that drug-induced as well as spontaneous attacks may be caused by NO [5]. Headache is the most prominent adverse effect of nitrate therapy in sufferers of cardiovascular diseases [6]. However, during long-term nitrate treatment, headache often abates over a period of time, whilst the anti-anginal effect remains, implying tolerance in cephalic more than in coronary arteries. Human data on the development of nitrate tolerance in different cranial arteries are currently lacking. A correlation between the vascular adaptation and tolerance to headache could lead to insight into vascular headache mechanisms in general. We therefore investigated the development of nitrate tolerance in the middle cerebral, superficial temporal, and radial arteries during oral administration of controlled release formulation of 5 -ISMN $(30 \mathrm{mg} \times 3)$ for 7 days and compared the results to the headache response previously published [7]. 


\section{Methods}

Material, design and measurements

A total of 16 healthy subjects, 15 females and 1 male, aged 30-51 years (mean 38.7 years) participated in the study. Subjects with a history of migraine and subjects with other headaches more than 1 day/month, subjects on daily medication other than contraceptives, and pregnant and nursing women were excluded. Prior to inclusion in the study all subjects had experienced headache, but no hypotension after a test dose of $0.5 \mathrm{mg}$ glyceryl trinitrate administered sublingually. An interval of at least 3 days separated the study period from the day of test dose given. Weak analgesics (paracetamol, acetylsalicylic acid), antiemetic (metoclopramide), tea, coffee, alcohol or tobacco were not allowed from $8 \mathrm{~h}$ prior to the haemodynamic measurements, neither were vasoactive migraine drugs (triptans) $24 \mathrm{~h}$ before the measurements. The study followed the Helsinki II declaration and was approved by the National Board of Health and also by the Ethics Committee of the County of Copenhagen. All subjects gave their written informed consent and were free to withdraw at any time and to receive treatment if needed.

The study followed a double blind, randomised, placebo controlled cross-over design. 5-ISMN $30 \mathrm{mg}$ in a controlled release formulation (Imdur ${ }^{\circledR}$ AstraZeneca) or placebo was administered orally three times a day during two separate periods of 7 days, each period being separated from the other by at least a fortnight of wash-out. The time-averaged mean of the maximal blood velocities $\left(V_{\text {mean }}\right)$ in both middle cerebral arteries (MCA) was measured with transcranial Doppler (Transscan, EME) [8]. The fixpoint measurement of $V_{\text {mean }}$ was a point along the MCA, which was free of the bifurcation between the MCA and the anterior cerebral artery, but as close to it as possible [9]. This fixpoint was then used throughout the study in each individual, and every measurement was done after carefully optimising the signal from this point. The diameters of the left radial artery and both temporal arteries were measured with a high resolution ultrasound scanning (Dermascan C, Cortex Technology) [10]. A mean of four measurements performed within $30 \mathrm{~s}$ was used to augment precision. An individual fixpoint of each subject along the right frontal branch of the superficial temporal artery and along the radial artery of the left wrist was used throughout the study. Day to day positions of measurements were reproduced by recording the scanning position in relation to the angle and distance relative to the orbito-meatal line (temporal artery) and to the distal volar crest of the wrist (radial artery) [10, 11]. Blood pressure and heart rate were measured with an automatic inflatable arm cuff (Tonoprint).
Procedure

The subjects arrived in the laboratory at 09.00 hours. After 30 min of rest in the supine position, baseline values of $V_{\text {mean }}$ of MCA, diameters of the temporal and radial arteries, blood pressure and heart rate were recorded, followed by an oral administration of $30 \mathrm{mg}$ 5-ISMN or placebo. The subjects were then allowed to leave the laboratory, but instructed to return $4 \mathrm{~h}$ later for a repetition of the haemodynamic measurements, preceded by $30 \mathrm{~min}$ of supine rest. Afterwards the subjects were discharged from hospital and asked to return to the laboratory for repeated measurements the next day, and after 3 and 7 days at 11.00 hours (i.e. at time of peak plasma concentration, $4 \mathrm{~h}$ post morning dose at 07.00 hours [4]). Headache severity was scored on a numerical verbal rating scale from 0 to 10 (1 representing a prepain, including a feeling of pressure and pulsation, 5 a moderate headache, and 10 the worst possible headache [7]. This was scored in a headache diary every day at 07.00, 15.00, 18.00, and 22.00 hours. Each subject was offered paracetamol/acetyl-salicylic acid for immediate or later use, if headache became intolerable. 5-ISMN or placebo was administered for 7 days by the subjects themselves at home at 07.00, 15.00 and 22.00 hours. At each visit, compliance was tested by capsule count.

\section{Statistical analysis}

The arterial responses were calculated in per cent of baseline and expressed as mean and standard error of the mean $( \pm$ SEM $)$, unless otherwise specified. Side-to-side differences between the right and left middle cerebral artery/temporal artery were analysed, using a $t$ test for paired data. Overall differences between periods (5-ISMN/ placebo) were evaluated by multivariate (three-way) analysis of variance at $0,4,24,72$ and $168 \mathrm{~h}$. Changes over time were analysed separately and significant changes located by a multi-comparison procedure (range test, confidence level 95\%) [12] Statgrafics 3.0 was used throughout for statistical analysis. For all analyses, a $p$ value $<0.05$ was considered statistically significant.

\section{Results}

Five of 16 subjects withdrew within $24 \mathrm{~h}$ from start of the 5-ISMN period because of adverse effects [unacceptable headache (1 subject), symptoms compatible with hypotension (vertigo) (3 subjects), nausea (1 subject)]. Data from these subjects were excluded from the statistical analysis. 
Table $1 V_{\text {mean }}$ of the middle cerebral artery (MCA) and diameters of the temporal (TA) and radial arteries (RA) during 5-ISMN and placebo [mean (absolute values), SEM]

\begin{tabular}{|c|c|c|c|c|c|c|}
\hline \multirow{2}{*}{$\begin{array}{l}\text { Time } \\
\text { Hours }\end{array}$} & \multicolumn{2}{|c|}{$V_{\text {mean }}, \mathrm{MCA}(\mathrm{cm} / \mathrm{s}, \mathrm{SEM})$} & \multicolumn{2}{|c|}{ Diameter, TA (mm, SEM) } & \multicolumn{2}{|c|}{ Diameter, RA (mm, SEM) } \\
\hline & 5-ISMN & Placebo & 5-ISMN & Placebo & 5-ISMN & Placebo \\
\hline 0 & 71 (4) & 71 (4) & $0.95(0.04)$ & $0.98(0.04)$ & $2.42(0.09)$ & $2.46(0.09)$ \\
\hline 4 & $58(3)$ & 67 (4) & $1.09(0.04)$ & $1.01(0.04)$ & $3.08(0.17)$ & $2.61(0.13)$ \\
\hline 24 & $66(4)$ & 69 (4) & $1.15(0.03)$ & $0.98(0.03)$ & $3.08(0.12)$ & $2.62(0.11)$ \\
\hline 72 & $68(3)$ & $70(3)$ & $1.11(0.05)$ & $0.97(0.03)$ & $3.18(0.15)$ & $2.56(0.09)$ \\
\hline 168 & $68(3)$ & $69(3)$ & $1.03(0.04)$ & $0.98(0.04)$ & $2.82(0.13)$ & $2.58(0.11)$ \\
\hline
\end{tabular}

$M C A$ middle cerebral artery, $T A$ temporal artery, $R A$ radial artery, $V_{\text {mean }}$ mean blood velocity, $S E M$ standard error of the mean

Haemodynamic values at each investigative time point are presented in Tables 1 and 2 (absolute values). To facilitate a survey, and since no systematic side-to-side differences were found $(p>0.05)$, the results from the right- and left-sided arteries are presented as mean values. None of the pre-treatment values differed significantly between the two study periods ( $p>0.05, t$ test for paired data).

Changes in the middle cerebral artery

5-ISMN decreased $V_{\text {mean }}$ compared to placebo $(p=0.02)$. At $4 \mathrm{~h}$ after administration of 5-ISMN, $V_{\text {mean }}$ had decreased to $83 \pm 3 \%$ of baseline $(p<0.05)$. However, after $24 \mathrm{~h}$ this effect was no longer present. No significant changes over time were observed during placebo $(p=0.25)$.

Changes in the temporal and radial arteries

5-ISMN dilated the arteries compared to placebo ( $p=0.0001$, temporal artery; $p=0.0001$, radial artery). At $4 \mathrm{~h}$ post 5 -ISMN administration the temporal artery was dilated to $116 \pm 3 \%$ of baseline $(p<0.05)$. Maximal dilatation to $124 \pm 4 \%$ of baseline was measured $20 \mathrm{~h}$ later $(p<0.05)$. After 3 days, an attenuation of this effect to $119 \pm 5 \%$ of baseline was observed; however, this was not significant ( $p>0.05$, range test). After 7 days partial tolerance of the temporal artery had developed (109 $\pm 3 \%$ of baseline); thus, a significant attenuation of dilatory effect was observed compared to peak value at $24 \mathrm{~h}$ $(p<0.05)$, but the artery was still significantly dilated compared to baseline $(p<0.05)$ (Fig. 1).

Four hours post 5-ISMN administration the radial artery was dilated to $127 \pm 5 \%$ of baseline $(p<0.05)$. No further change was observed at 24 and $72 \mathrm{~h}(p>0.05$, range test). After 7 days a significant attenuation compared to the preceding values at 24 and $72 \mathrm{~h}(p<0.05)$ was observed but the artery was still significantly dilated compared to baseline $(117 \pm 4 \%$ of baseline $)(p<0.05)$.

No significant changes over time were detected during placebo $(p=0.38$, temporal artery; $p=0.19$, radial artery).

Heart rate and blood pressure

5-ISMN did not change the responses compared to placebo $(p>0.05)$. Systolic and diastolic blood pressure showed no changes at 4 and $24 \mathrm{~h}$ post 5-ISMN; however, systolic and diastolic blood pressure increased after 3 days compared to values at 4 and $24 \mathrm{~h}(p<0.05)$. This effect was not present after 7 days $(p>0.05)$. No significant changes of blood pressure over time were observed during placebo $(p>0.7)$. No significant changes of heart rate over time

Table 2 Blood pressure and heart rate during 5-ISMN and placebo [mean (absolute values), SEM]

\begin{tabular}{|c|c|c|c|c|c|c|}
\hline \multirow{2}{*}{$\begin{array}{l}\text { Time } \\
\text { Hours }\end{array}$} & \multicolumn{2}{|c|}{ Systolic blood pressure (mmHg, SEM) } & \multicolumn{2}{|c|}{ Diastolic blood pressure (mmHg, SEM) } & \multicolumn{2}{|c|}{ Heart rate (Beats/min, SEM) } \\
\hline & 5-ISMN & Placebo & 5-ISMN & Placebo & 5-ISMN & Placebo \\
\hline 0 & $111(4)$ & $108(2)$ & $70(3)$ & $74(3)$ & $66(3)$ & $65(2)$ \\
\hline 4 & $108(4)$ & $109(2)$ & $68(4)$ & $71(4)$ & $67(1)$ & $67(2)$ \\
\hline 24 & $109(5)$ & $106(4)$ & $68(4)$ & $70(4)$ & $66(3)$ & $65(2)$ \\
\hline 72 & $115(3)$ & $107(4)$ & $75(3)$ & $71(5)$ & $68(2)$ & $68(2)$ \\
\hline 168 & $112(4)$ & 108 (4) & $72(4)$ & $70(3)$ & $73(3)$ & $75(2)$ \\
\hline
\end{tabular}

SEM standard error of the mean 


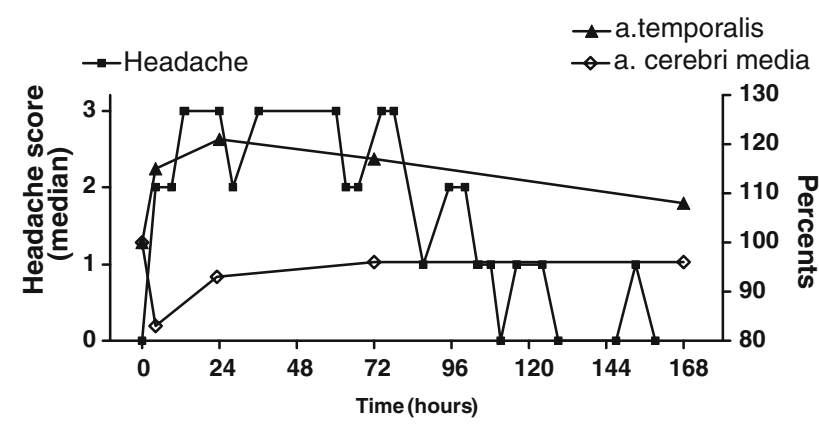

Fig. 1 The effect of 5-ISMN $30 \mathrm{mg}$ t.i.d for 7 days on headache, mean blood flow velocity in middle cerebral artery and diameter of temporal artery. Headache was rated on a $0-10$ scale. Median values are given. Percentage changes are given for the arteries. A close temporal association between the disappearance of headache and attenuation of the dilatory potency of 5-ISMN in the temporal artery was observed. The intracranial artery (middle cerebral artery) was already tolerant within $24 \mathrm{~h}$

was observed during 5-ISMN ( $p=0.23$ ) while heart rate increased significantly after 7 days compared to baseline during placebo $(p<0.05)$.

\section{Discussion}

This study shows that the development of tolerance to NO is fast in the middle cerebral artery but slow in extracerebral arteries and that tolerance in headache similarly develops slowly.

Nitrate tolerance is a complex phenomenon, which involves neurohormonal counter-regulation, collectively classified as pseudotolerance, a well as intrinsic vascular processes, defined as vascular tolerance [13].

An isosorbide 5-mononitrate (5-ISMN) dose of $30 \mathrm{mg}$ was chosen because a previously performed dose-response study showed that this dose induced significant changes in the radial- and temporal arterial diameters and no major drops in blood pressure or other severe adverse effects [4]. It is probably the maximum tolerable dose when given thrice daily because 5 out of 16 subjects discontinued the study early due to adverse events, see results. 5-ISMN t.i.d was chosen as the NO donor because of its long half life of 4-5 h [14, 15]. In addition, a controlled release formulation was used. Given thrice daily it results in a rather continuous exposure to NO thus enhancing the development of tolerance [16].

Regional cerebral blood flow (rCBF) was not measured in the present study, but in single-dose studies with GTN have shown either an unchanged $\mathrm{rCBF}$ in two SPECT (single photon emission computed tomography) studies $[17,18]$ and in one PET (positron emission tomography) study [19] or a $23 \%$ increase in one PET study [20]. Although the Doppler technique does not allow direct measurements of the diameter of the middle cerebral artery (MCA), the relative diameter change can be estimated from the relation: regional cerebral blood flow $(\mathrm{rCBF})=$ mean velocity $\times$ cross sectional area of the artery [21]. Whether unchanged or slightly increased $\mathrm{rCBF}$ is present a decrease in $V_{\text {mean }}$, as in the present study, will indicate a dilatation of MCA. With an unchanged rCBF it can be estimated that 5ISMN caused a $10 \%$ increase in the diameter of the middle cerebral artery (MCA). If the $\mathrm{rCBF}$ is increased the increase of the diameter of the MCA would be more pronounced. The decrease of $V_{\text {mean }}$ of $17 \%$ is in the same range as found previously in healthy subjects (20\%) after i.v. GTN $0.5 \mu \mathrm{g} /(\mathrm{kg} \mathrm{min})$ in a study where $\mathrm{rCBF}$ was measured simultaneously with SPECT and was unchanged [18]. This is somewhat less than the decrease of $28 \%$ observed with half the dose of GTN in migraine patients [22]. A comparable decrease $(13 \%)$ in $V_{\text {mean }}$ was found in another study in healthy volunteers after i.v. GTN $0.5 \mu \mathrm{g} /(\mathrm{kg} \min )$ [23].

In one study transdermal GTN $(0.6 \mathrm{mg} / \mathrm{h})$ for 7 days was found to induce tolerance to GTN as measured by forearm blood volume [24] whereas pentaerythritol tetranitrate $(60 \mathrm{mg}$ three times a day) did not have this effect [24]. The few existing clinical studies, using direct measurements of diameter changes of the radial and temporal arteries, have failed to demonstrate the appearance of nitrate tolerance in these vessels within a study period of 7 [25] and 24-48 h of continuous GTN-infusion [26, 27]. The present study provides long-term data, up to a week, on this phenomenon in the radial and superficial temporal arteries for the first time. It is also the first clinical study of nitrate tolerance in cerebral arteries, the time course of which furthermore is compared to those of the temporal and radial arteries. At $4 \mathrm{~h}$ after administration of the first dose of 5-ISMN a significant dilatation was observed in both cephalic and limb arteries. Complete tolerance occurred already within $24 \mathrm{~h}$ of the first dose (a total of four doses) in the middle cerebral artery. At $168 \mathrm{~h}$ (day seven) partial tolerance was observed in the temporal and radial arteries compared to peak values but the radial was still dilated compared to baseline. The partial tolerance of the temporal and radial arteries may, however, have developed earlier than at $168 \mathrm{~h}$ as no measurements were done in the interval between 72 and $168 \mathrm{~h}$. Previous studies [26-28], investigating the effects of nitrates on the temporal and radial arteries, were not extended until the development of tolerance, but support nevertheless the present finding of a relatively late occurrence of tolerance in these vessels. Thus, during $7 \mathrm{~h}$ of GTN-infusion in healthy subjects the mean dilatation of the radial artery was $36 \%$ after $5 \mathrm{~min}$ of infusion of $0.5 \mu \mathrm{g} /(\mathrm{kg} \mathrm{min})$ and remained stable over time [25]. In one study, GTN $0.5 \mu \mathrm{g} /$ (kg min) was infused for $24 \mathrm{~h}$ in healthy subjects; 
diameters of the radial and temporal arteries increased significantly after $1 \mathrm{~h}$ of infusion followed by an attenuation of this effect but tolerance was not observed [26]. In another study, GTN GTN $0.5 \mu \mathrm{g} /(\mathrm{kg} \min )$ was infused for $48 \mathrm{~h}$ in healthy subjects with no attenuation of the dilator effect on the radial artery [27].

In vitro studies confirm a faster development of nitrate tolerance in the intracranial arteries compared to peripheral arteries [29, 30]. Thus, in smooth muscle cells cultured from peripheral vessels, pre-treatment with GTN was requested for $60 \mathrm{~min}$ in order to induce tolerance [29]. In contrast, in smooth muscle cells from cerebral arteries a 5minute pre-treatment with GTN reduced the response to rechallenge by $>50 \%$ [30]. Also, time to recovery from tolerance was shorter in cerebral artery smooth muscle cells than in peripherally derived cells [30]. Collectively these and other in vitro data [31-33] demonstrate that vascular tolerance to NO-producing agents can be accounted for by actions at the cell level [31-33]. Such intrinsic abnormalities include decreased biotransformation of organic nitrates to NO, desensitisation of the target enzyme guanylyl cyclase, enhanced vascular superoxide anion production, which degrades $\mathrm{NO}$, and enhanced propensity for vasoconstriction due to increased endothelin expression within the vascular smooth muscle [31-34]. Inhibition of mitochondrial aldehyde dehydrogenase (ALDH-2) has in several studies been shown to be involved in the development of tolerance to GTN [35-38] and GTN tolerance was described as a syndrome characterized by mitochondrial dysfunction [37]. Bioactivation of 5-ISMN, however, presumably involves an ALDH-2-independent pathway [36] and alternative explanations for the tolerance to 5-ISMN should be investigated, see [13]. In the clinical setting other mechanisms of tolerance than those at a cellular level are considered to play a major role including a neurohormonal counter regulation with response of the sympathoadrenal axis and of the renin-angiotensin system that counteracts the effects of the drug [13, 34]. For a recent review on nitrate tolerance, see [13]. Cellular and systemic mechanisms have most likely a differentiated impact on arteries of different origin resulting in the different time-effect curves as observed in the present study.

A possible mechanism whereby NO could cause headache is by dilatation of cerebral and extracerebral blood vessels. This concept is supported by studies in which arterial dilatation during and after infusion of GTN or oral administration of 5-ISMN was consistently observed [4, 17, 18]. The present study demonstrated a significant dilatation of both MCA, temporal and radial arteries at $4 \mathrm{~h}$ after administration of the first dose of 5-ISMN. The 5-ISMNinduced headache was most severe during the first couple of days after 5-ISMN administration, followed by a gradual attenuation, until a state of tolerance to headache had developed on the 6th day [7]. A close temporal association between the disappearance of headache and attenuation of the 5-ISMN induced dilatation of the superficial temporal artery was observed (Fig. 1). In contrast, tolerance in the middle cerebral artery was complete and appeared already after $24 \mathrm{~h}$, i.e. earlier than the development of tolerance to headache (Fig. 1). The fact that the temporal artery was still dilated to a minor degree after 7 days, whereas headache had disappeared indicates that there is most likely a threshold for NO-induced headache. These findings suggest that the locus of nociception in nitrate-induced headache could be related to dilatation of extracerebral arteries including possibly the middle meningeal artery, also a branch: of the external carotid artery [39].

The present study of NO-induced headache does not exclude the involvement of intracranial arteries in migraine that may be caused by dilatation independent pain-inducing effects of NO. Thus, migraine pain may possibly arise from normally calibrated arteries due to sensitization of perivascular sensory nerve terminals [40].

In conclusion, the development of nitrate tolerance is faster and more complete in cerebral arteries than in smallsized extracranial and middle-sized limb arteries. This may reflect differentiated impact of cellular and systemic mechanisms of tolerance in arteries of different size and origin. If vasodilatation is the cause of NO-induced headache, our results point to extracerebral arteries as the locus of nociception.

Acknowledgments The study was supported by the University of Copenhagen, the Danish Headache Society and the Lundbeck Foundation via the Lundbeck Foundation Center for Neurovascular Research (LUCENS). We are indebted to Ms Bente Leisner and Ms Kirsten Enghave for excellent and careful technical assistance in the laboratory.

Conflict of interest None.

\section{References}

1. Ignarro LJ, Lipton H, Edwards JC, Baricos WH, Hyman AL, Kadowitz PJ, Gruetter CA (1981) Mechanisms of vascular smooth muscle relaxation by organic nitrates, nitrites, nitroprusside and nitric oxide: evidence for the involvement of $\mathrm{S}$ nitrosothiols as active intermediates. J Pharmacol Exp Ther 218:739-749

2. Moncada S, Higgs EA (1991) Endogenous nitric oxide: physiology, pathology and clinical relevance. Eur $\mathrm{J}$ Clin Invest 21:361-374

3. Iversen HK, Olesen J (1996) Headache induced by a nitric oxide donor (nitroglycerin) responds to sumatriptan. A human model for development of migraine drugs. Cephalalgia 16:412-418

4. Iversen HK, Nielsen TH, Garre K, Tfelt-Hansen P, Olesen J (1992) Dose-dependent headache response and dilatation of limb and extracranial arteries after three doses of 5-isosorbide-mononitrate. Eur J Clin Pharmacol 42:31-35 
5. Olesen J, Thomsen LL, Iversen HK (1994) Nitric oxide is a key molecule in migraine and other vascular headaches. Trends Pharmacol Sci 15:149-153

6. Fletcher A, McLoone P, Bulpitt C (1988) Quality of life on angina therapy: a randomized controlled trial of transdermal glyceryl trinitrate against placebo. Lancet 2(8601):4-8

7. Christiansen I, Iversen HK, Olesen J (2002) Headache characteristics during the development of tolerance to nitrites. Pathophysiological implications. Cephalalgia 20:437-444

8. Aaslid R, Markwalder TM, Nomes H (1982) Noninvasive transcranial Doppler ultrasound recording of flow velocity in basal cerebral arteries. J Neurosurg 57:769-774

9. Thomsen LL, Iversen HK (1993) Experimental and biological variation of three-dimensional transcranial Doppler measurements. J Appl Physiol 75:2805-2810

10. Nielsen TH, Iversen HK, Tfelt-Hansen P, Olesen J (1993) Small arteries can be accurately studied in-vivo, using high frequency ultrasound. Ultrasound Med Biol 19:717-725

11. Nielsen TH, Iversen HK, Tfelt-Hansen P (1990) Determination of the luminal diameter of the radial artery in man by high frequency ultrasound: a methodological study. Ultrasound Med Biol 16:789-791

12. Matthews JNS, Altman DG, Cambell MJ, Royston P (1990) Analysis of serial measurements in medical research. MBJ 300:230-235

13. Münzel T, Daiber A, Mülsch A (2005) Explaining the phenomenon of nitrate tolerance. Circ Res 97:618-628

14. Taylor T, Chasseaud LF, Major R, Doyle E, Darragh A (1981) Isosorbide 5-mononitrate pharmacokinetics in humans. Biopharm Drug Dispos 2:255-263

15. Major RM, Taylor T, Chasseaud LF, Darragh A, Lambe RF (1984) Isosorbide 5-mononitrate kinetics. Clin Pharmacol Ther 35:653-659

16. Wagner F, Siefert F, Trenk D, Jänchen E (1990) Relationship between pharmacokinetics and hemodynamic tolerance to isosorbide-5-mononitrate. Eur J Clin Pharmacol 38(Suppl 1):S53S59

17. Dahl A, Russell D, Nyberg-Hansen R, Rootwell K (1989) Effect of nitroglycerin on cerebral circulation measured by transcranial Doppler and SPECT. Stroke 20:173-176

18. Iversen HK, Friberg L, Holm S, Tfelt-hansen P (2008) Intracranial hemodynamics during intravenous infusion of nitroglycerin. $\mathrm{J}$ Headache Pain (in press)

19. White RP, Deane C, Hindley C, Bloomfield PM, Cunningham VJ, Vallance $P$ et al (2000) The effect of the nitric oxide donor glyceryl trinitrate on global and regional cerebral blood flow in man. J Neurol Sci 178:23-28

20. Bednarczyk EM, Wack DS, Kassab MY, Burch K, Trinidad K, Haka M, Gona J (2002) Brain blood flow in the nitroglycerin (GTN) model of migraine: measurement using positron emision tomography and transcranial Doppler. Cephalalgia 22:749-757

21. Friberg L, Olesen J, Iversen HK, Sperling B (1991) Migraine pain associated with middle cerebral artery dilatation: reversal by sumatriptan. Lancet 338:13-17

22. Thomsen LL, Iversen HK, Brinck TA, Olesen J (1993) Arterial supersensitivity to nitric oxide (nitroglycerin) in migraine sufferers. Cephalalgia 13:395-399

23. Schmetterer L, Woltz M, Krejcy K, Graselli U, Findl O, Eichler HG, Singer EA (1996) Cerebral and ocular hemodynamic effects of sumatriptan in the nitroglycerin headache model. Clin Pharmacol Ther 60:199-205

24. Jurt U, Gori T, Ravandi A, Babaei S, Zeman P, Parker JD (2001) Differential effects of pentaerythritol tetranitrate and nitroglycerin on the delopment of tolerance and evidence: a human in vivo study. J Am Coll Cardiol 38:854-859

25. Iversen HK, Nielsen TH, Tfelt-Hansen P, Olesen J (1993) Lack of tolerance of headache and radial artery diameter during a 7 hour intravenous infusion of nitroglycerin. Eur $\mathrm{J}$ Clin Pharmacol 44:47-50

26. Boesgaard S, Iversen H, Wroblewski H, Poulsen HE, Frandsen H, Kastrup J, Aldershvile J (1994) Altered peripheral vasodilatory profile of nitroglycerin during long-term infusion of $\mathrm{N}$-acetylcystein. J Am Coll Cardiol 23:163-169

27. Jeserich M, Münzel T, Pape L, Fischer C, Drexler H, Just H (1995) Absence of vascular tolerance in conductance vessels after 48 hours of intravenous nitroglycerin in patients with coronary artery disease. J Am Coll Cardiol 26:50-56

28. Zhang LM, Castresana MR, Newman WH (1994) Tolerance to nitroglycerin in vascular smooth muscle cells: recovery and cross-tolerance to sodium nitroprusside. Anesth Analg 78:10531059

29. Tao H, Zhang LM, Castresana MR, Newman WH, Shillcutt SD (1997) Response of cultured cerebral artery smooth muscle cells to the nitric oxide vasodilator, nitroglycerin and sodium nitroprusside. J Neurosurg Anesth 1:58-64

30. Elkayam U (1991) Tolerance to organic nitrates: evidence, mechanisms, clinical relevance and strategies for prevention. Ann Int Med 114:667-677

31. Münzel T, Sayegh H, Freeman BA, Tarpey MM, Harrison DG (1995) Evidence for enhanced vascular superoxide anion production in nitrate tolerance: a novel mechanism of tolerance and cross tolerance. J Clin Invest 95:187-194

32. Münzel T, Giaid A, Kurz S, Stewart D, Harrison D (1995) Evidence for a role of endothelin-1 and protein kinase $\mathrm{C}$ in nitrate tolerance. Proc Natl Acad Sci USA 92:5244-5248

33. Szöcs K, Lasseque B, Wenzel P, Wendt M, Daiber A, Oelze M, Meinertz T, Münzel T, Baldus S (2007) Increased superoxide production in nitrate tolerance is associated with $\operatorname{NAD}(\mathrm{P}) \mathrm{H}$ oxidase and aldehyde dehydrogenase 2 downregulation. J Mol Cell Cardiol 42:1111-1118

34. Parker JD, Farrell B, Fenton T, Cohanim M, Parker JO (1991) Counter-regulatory responses to continuous and intermittent therapy with nitroglycerin. Circulation 84:2336-2345

35. Chen YR, Nie SD, Shan W, Jiang DJ, Shi RZ, Zhou Z et al (2007) Decrease in endogenous CGRP release in nitroglycerin tolerance: role of ALDH-2. Eur J Pharmacol 571:44-50

36. Daiber A, Oelze M, Coldeway M, Bachsmid M, Wenzel P, Sydow K et al (2004) Oxidative stress and mitochondrial aldehyde dehydrogenase activity: a comparison of pentaerythritol with other organic nitrates. Mol Pharmacol 66:1372-1382

37. Sydow K, Daiber A, Oelze M, Chen Z, August M, Wendt M et al (2004) Central role of mitochondrial aldehyde dehydrogenase and reactive oxygen species in nitroglycerin tolerance and cross-tolerance. J Clin Invest 113:482-489

38. Hink U, Daiber A, Kayhan N, Trischler J, Kattz C, Oelze M et al (2007) Oxidative inhibition of mitochondrial aldehyde dehydrogenase promotes nitroglycerin tolerance in human blood vessels. J Am Coll Cardiol 50:2226-2232

39. Schoonman GG, Bakker D, Schmitz N, van der Geest RJ, van der Grond J, Ferrari MD, van Buchem MA (2006) Magnetic resonance angiography of the human meningeal artery: implications for migraine. J Magn Reson Imaging 24:918-921

40. Kruuse C, Thomsen LL, Birk S, Olesen J (2003) Migraine can be induced by sildefanil without changes in middle cerebral artery diameter. Brain 126:241-247 